\title{
IMIII Telephone-Delivered Behavioral Skills Intervention for African American Adults with Type 2 Diabetes: A Randomized Controlled Trial
}

\author{
Leonard E. Egede, $M D, M S^{1,2,3}$, Joni S. Williams, MD, MPH ${ }^{1,2,3}$, Delia C. Voronca, $P h D^{4}$, \\ Mulugeta Gebregziabher, $P h D^{5}$, and Cheryl P. Lynch, MD, MPH
}

'Department of Medicine, Froedtert and Medical College of Wisconsin, Milwaukee, WI, USA; ${ }^{2}$ Center for Patient Care and Outcomes Research, Medical College of Wisconsin, Milwaukee, WI, USA; ${ }^{3}$ Division of General Internal Medicine, Froedtert and Medical College of Wisconsin, Milwaukee, WI, USA; ${ }^{4}$ Emmes, Vaccine and Infectious Diseases, Rockville, MD, USA; ${ }^{5}$ Department of Public Health Sciences, Medical University of South Carolina, Charleston, SC, USA; ${ }^{6}$ Center for Health Disparities Research, Medical University of South Carolina, Charleston, SC, USA; ${ }^{7}$ Department of Medicine, Division of General Internal Medicine and Geriatrics, Medical University of South Carolina, Charleston, SC, USA; ${ }^{8} \mathrm{Health}$ Equity and Rural Outreach Innovation Center, Ralph H. Johnson VA Medical Center, Charleston, SC, USA.

BACKGROUND: Diabetes disproportionately affects African Americans and is associated with poorer outcomes. Selfmanagement is important for glycemic control; however, evidence in African Americans is limited.

OBJECTIVE: To assess the efficacy of a combined telephone-delivered education and behavioral skills intervention (TBSI) in reducing hemoglobin Alc (HbAlc) levels in African Americans with type 2 diabetes, using a factorial design.

DESIGN: This is a four-year randomized clinical trial, using a 2 × 2 factorial design.: Participants: African American adults $\geq 18$ years) with poorly controlled type 2 diabetes (HbAlc $\geq 9 \%$ ) were randomly assigned to one of four groups: 1) knowledge only, 2) skills only, 3) combined knowledge and skills (TBSI), or 4) control group. Intervention: All participants received 12 telephone-delivered 30min intervention sessions specific to their assigned group. Participants were assessed at baseline and 3, 6, and 12 months. Main measure: The primary outcome was $\mathrm{HbAlc}$ at 12 months post-randomization in the intentto-treat (ITT) population.

KEY RESULTS: Two hundred fifty-five participants were randomly assigned to the four groups. Based on the ITT population after multiple imputation, the analysis of covariance with baseline $\mathrm{HbAlc}$ as the covariate showed that $\mathrm{HbAlc}$ at 12 months for the intervention groups did not differ significantly from that of the control group (knowledge: 0.49, $p=0.123$; skills: 0.23, $p=0.456$; combined: $0.48, p=$ 0.105). Absolute change from baseline at 12 months for all treatment arms was 0.6. Longitudinal mixed effects analysis showed that, on average, there was a significant decline in $\mathrm{HbAlc}$ over time for all treatment groups $(-0.07, p<0.001)$. However, the rates of decline for the intervention groups were not significantly different from that of the control group (knowledge: 0.06, $p=0.052$; skills: 0.02, $p=0.448$;

Egede LE, Strom JL, Durkalski VL et al. Rationale and design: telephonedelivered behavioral skills interventions for Blacks with Type 2 Diabetes. Trials 2010:11:35

Received August 23, 2016

Revised February 1, 2017

Accepted February 16, 2017

Published online March 23, 2017 combined: 0.05, $p=0.062$ ). Results from per-protocol populations were similar.

CONCLUSIONS: For African Americans with poorly controlled type 2 diabetes, combined education and skills training did not achieve greater reductions in glycemic control (i.e., HbAlc levels) at 12 months compared to the control group, education alone, or skills training alone. This trial is registered with ClinicalTrials.gov, identifier no. NCT00929838.

J Gen Intern Med 32(7):775-82

DOI: $10.1007 / \mathrm{s} 11606-017-4023-0$

(C) Society of General Internal Medicine 2017

\section{INTRODUCTION}

Diabetes affects over 29 million individuals in the United States and is associated with significant morbidity and mortality, increased health care utilization, and higher health care costs, accounting for an estimated $\$ 245$ billion in total expenditures annually. ${ }^{1}$ Diabetes disproportionately affects nonHispanic blacks (NHBs) and is associated with poorer outcomes, negative beliefs and attitudes towards diabetes, inadequate self-management, and worse perceived control. ${ }^{1-7}$ There is compelling evidence that self-management is important for improving glycemic control. ${ }^{8-13}$ In fact, one meta-analysis of 31 randomized controlled trials found that self-management education interventions led to a $0.76 \%$ reduction in glycosylated hemoglobin A1c (HbA1c) levels (95\% confidence interval $0.34-1.18) .{ }^{10}$ In addition, evidence supports the efficacy of telephone interventions in improving patient outcomes. ${ }^{14-16}$ Such studies in NHBs, however, are limited.

A number of studies involving various knowledge and information, motivation and coping, and behavioral and skills training interventions have shown mixed results. ${ }^{17-27}$ While some have demonstrated significant improvements in glycemic control or self-management, ${ }^{17,23,24}$ others have reported less favorable results. ${ }^{17,22,24}$ A systematic review of diabetes self-management interventions suggests that intervention effects can vary depending on the mode of delivery, hours of engagement, and baseline 
HbA1c at the time of enrollment. ${ }^{25}$ Results can be further complicated when targeting a vulnerable population such as NHBs, where factors such as cultural relevance, social support, and subsistence needs (e.g., transportation, access, caregiver responsibilities) should be considered. ${ }^{17,20,23,27}$

Overall, the generalizability of prior studies is limited by 1) the recruitment of insufficient numbers of NHBs; 2) a lack of randomized controlled trials comparing critical aspects of the interventions such as knowledge, behavioral modification, and skills training independently or in combination; 3) poor internal validity; 4) inadequate dosage and frequency of the intervention, coupled with minimal patient-centeredness and tailoring; and 5) a limited number of interventions based on behavioral theories such as motivational interviewing. Therefore, this study was designed to test the efficacy of separate and combined telephone-delivered diabetes knowledge and behavioral skills training in high-risk NHB adults with poorly controlled type 2 diabetes. We hypothesized that the results for patients in the separate and combined interventions would be superior to those in the control group regarding the reduction in $\mathrm{HbAlc}$ at $12-$ month follow-up.

\section{METHODS}

\section{Study Design and Participants}

The study design featured a $2 \times 2$ factorial randomized controlled trial (RCT) with a follow-up period of 12 months. ${ }^{28}$ Assessment visits were conducted at baseline and at 3, 6, and 12 months. The study participants were high-risk NHBs with poorly controlled type 2 diabetes $(\mathrm{HbA} 1 \mathrm{c} \geq 9 \%$ within 12 months of randomization) who were recruited mainly from clinics (general internal medicine, endocrinology, family medicine, and community primary care) at the Medical University of South Carolina (MUSC; general internal medicine, endocrinology, family medicine, and community primary care clinics) and the Ralph H. Johnson Veterans Administration Medical Center (VAMC), both located in Charleston, South Carolina.

NHB patients with type 2 diabetes were identified using (1) clinic billing records for ICD-9 codes consistent with a diagnosis of type 2 diabetes, and (2) referrals from physicians and other clinic staff such as nurses, or patients themselves. Letters of invitation signed by the patients' primary care providers were mailed to patients, and institutional review board (IRB)-approved recruitment flyers were posted in prominent locations in the study clinics. Patients eligible to participate in the study were 18 years of age and older, had a clinical diagnosis of type 2 diabetes and $\mathrm{HbAlc} \geq 9 \%$ at screening, self-identified as nonHispanic black or African American, were taking at least one oral medication for hypertension or hyperlipidemia and were willing to use an electronic compliance monitor (eCAP) bottle for 12 months, were able to communicate in English, and had access to a telephone (landline or cell phone) for the 12-week intervention period. Patients who had mental confusion on interview suggesting significant dementia, were participating in other diabetes clinical trials, had alcohol or drug abuse/dependency, had active psychosis or acute mental disorder, or had a life expectancy less than 6 months were excluded from the study. Eligible participants received $\$ 25$ at the completion of each assessment at baseline and 3, 6, and 12 months, for a total of $\$ 100.00$. All study procedures were approved by the MUSC IRB and the Research and Development (R\&D) Committee at the Ralph H. Johnson VAMC.

\section{Randomization and Blinding}

After being provided with a study overview and explanation of the procedures, risks, and benefits by the program assistants, participants signed the informed consent forms. Per proto$\mathrm{col},{ }^{28}$ all eligibility criteria were verified at the baseline visit by the health educators (HEs), who then randomized the participants into one of the four study arms: (1) diabetes knowledge group, (2) skills training group, (3) combined knowledge and skills training group, or (4) control group (usual standard of care plus general health education). The randomization was performed in waves, with approximately 64 patients randomized every 6 months. The randomization sequence was web-based and computer-generated. In addition to verifying eligibility, the HEs were responsible for randomizing the participants and conducting the 12-week intervention.

To prevent bias in the evaluation of outcomes, the treating physicians, clinic staff, and the research assistant who collected primary data on outcomes were blinded to treatment assignment. In addition, the patients were blinded to treatment assignment, and received treatment over the telephone for the same time and treatment interval (i.e., weekly calls of minimum of $30 \mathrm{~min}$ on the same day at the same time for 12 weeks).

\section{Clinical Interventions}

Details about the specific content of the interventions have been published previously. ${ }^{17}$ All intervention sessions were delivered by telephone. The proposed separate and combined interventions were based on the information-motivationbehavioral (IMB) skills model. ${ }^{29,30}$ Per the IMB model adapted to diabetes, information on diabetes is a prerequisite for appropriate diabetes self-management, motivation determines the adherence to diabetes self-management instructions, and behavioral skills are a major prerequisite for effective diabetes self-management. ${ }^{29-32}$

Regardless of the randomization group, all participants received 12 telephone sessions. Two full-time masters-level HEs, who were trained in behavioral skills counseling and the content and conduct of diabetes and general health education, delivered the weekly 30-min telephone calls to participants in all four study groups. Participants randomized to the diabetes knowledge group completed 12 diabetes education modules over the 12-week period. The educational materials were developed based on guidelines for diabetes education. ${ }^{33}$ Participants randomized to the skills group were administered 12 
sessions of behavioral skills training over the 12-week period, which focused on four behaviors: physical activity, diet, medication adherence, and blood glucose self-monitoring. For the participants in this group, the HEs, who were trained in motivational interviewing, worked with the patients to develop a patient-generated action plan for improving one targeted behavior over 3 weeks. In addition, participants in this group were given a list of five questions to ask their providers at every visit (patient activation) and were asked to complete a "Diabetes Care Package" (patient empowerment) during the first session. Participants randomized to the combined diabetes knowledge and skills intervention received weekly diabetes information, behavioral skills training, patient activation, and patient empowerment over the 12 -week period. To optimize time for the combined calls compared to the knowledge and skills only groups, education was covered in the first $10 \mathrm{~min}$ of the call, followed by $20 \mathrm{~min}$ for skills training. In addition to usual care, participants randomized to the control group received weekly general health education sessions (excluding diabetes education) over the 12-week period to control for attention. General health education sessions included topics such as back pain, sleep problems, stroke and transient ischemic attacks, vitamins, health care insurance basics, hepatitis, influenza and pneumonia, dyspepsia, colon cancer, migraine headaches, sore throat, and esophageal reflux. All sessions were audiotaped, and 20\% were randomly selected and reviewed by two co-investigators using a pre-defined template to assess inter-rater reliability on an item-by-item basis. There was $90 \%$ agreement between the two co-investigators that treatment fidelity was followed by the HEs.

Given the intensity of the intervention protocol, we ensured optimal compliance by (1) stressing the importance of attending the sessions, (2) making reminder telephone calls on the day or evening prior to each session, (3) requesting contact information for three of the participants' friends or relatives, (4) being flexible in accommodating participants' schedules when arranging weekly telephone calls, and (5) providing compensation for time devoted to study participation.

\section{Primary Outcome}

Glycosylated hemoglobin A1c (HbA1c) was measured at baseline and 3-, 6-, and 12-month visits. The primary outcome of interest was continuous HbA1c level at 12-month follow-up measured from blood specimens collected by trained phlebotomists/nurses.

\section{Statistical Analyses}

The power and sample size calculation specific to a $2 \times 2$ factorial design that tests three hypotheses suggested that a total of 42 participants per arm were required to achieve $85 \%$ power to detect a clinically relevant difference of one percentage point in $\mathrm{HbAlc}$ during the 12-month follow-up (assuming a common standard deviation of 1.5). Therefore, the total sample size required for a per-protocol (PP) analysis was
168 subjects. After accounting for anticipated 15\% attrition and $10 \%$ of randomized participants not attending the first treatment session, the total sample size needed for the intentto-treat (ITT) analysis was 255.

First, we looked at descriptive statistics of demographics and baseline clinical characteristics, overall and by treatment group. We assessed similarities between treatment groups and identified potential confounders to be used as covariates in subsequent analyses (chi-square tests for categorical variables and ANOVA tests for continuous variables).

Second, we performed primary and secondary analyses of the ITT population, which included all randomized participants who completed at least one treatment session. We used multiple imputations (MI) assuming data missing at random (MAR) to impute missing values of $\mathrm{HbA1c}$ for all randomized participants, and obtained complete data sets for each visit. The MI was implemented in SAS version 9.4 software (SAS Institute Inc., Cary, NC) using PROC MI (Markov chain Monte Carlo method), and the results from multiple imputed data sets were combined using PROC MIANALYZE via Rubin's rule. The variables used in the imputation model were age, education, gender, marital status, income, and diabetes duration.

For the primary statistical analyses, we performed an analysis of covariance (ANCOVA) on the ITT data after imputation to compare $\mathrm{HbAlc}$ levels between treatment groups at 12 months after adjusting for baseline levels of $\mathrm{HbAlc}$. We repeated the ANCOVA analysis, adjusting for possible confounders.

For the secondary analyses, we performed a mixed effects longitudinal analysis to assess differences in the rate of change in $\mathrm{HbA} 1 \mathrm{c}$ levels over time between treatment groups using a random intercept and slope longitudinal model. The longitudinal model included the treatment group, visit (time) as a continuous variable, and the interaction between treatment and visit as primary (fixed) independent variables. A significant interaction between visit and treatment would suggest that the rates of change over time were different between the treatment groups. We chose between a random intercept and a random intercept and slope based on a likelihood ratio test using maximum likelihood (ML) approximation. The above analyses were repeated for the PP population, defined as participants who completed all 12 education sessions and provided outcome measurements for all four visits, to evaluate the impact of missing data on study results.

\section{RESULTS}

\section{Trial Profile}

Between August 1, 2009, and March 31, 2011, we screened 443 patients, and the HEs randomly assigned 255 participants (intent-to-treat [ITT] population): $64(25 \%)$ in the control, 63 $(25 \%)$ in the knowledge only, 65 (25\%) in the skills only, and $63(25 \%)$ in the combined knowledge and skills group. There 


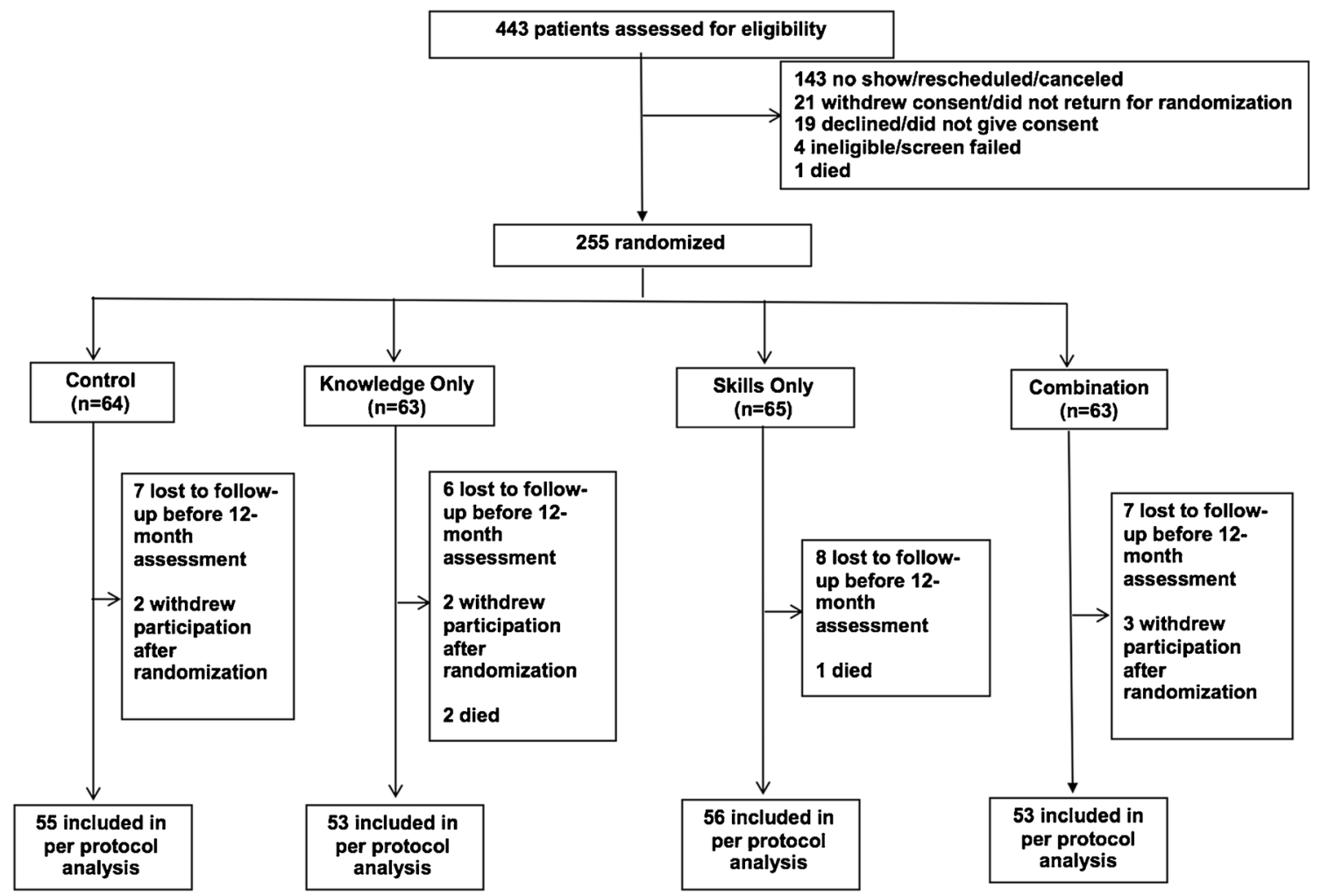

Figure 1 Trial profile (CONSORT diagram).

were $255(100 \%)$ patients at baseline; $217(85 \%)$ patients completed assessments at 3 months, 217 (85\%) at 6 months, and $217(85 \%)$ at 12 months. Figure 1 shows the flow of patients through the study (CONSORT diagram). There were $39(15 \%)$ participants with missing HbAlc measures at each of the study time points. The probability of missing $\mathrm{HbA} 1 \mathrm{C}$ at 12 months was not significantly associated with treatment group or with any demographics or other baseline characteristics at an 0.05 alpha level.

\section{Sample Demographics by Treatment Group}

In Table 1, we present characteristics of the ITT population at baseline. Most participants were men (55\%), with a mean age of 53 years, and most had government insurance (62\%). Among the four treatment arms, there were significant differences only in income levels $(p=0.013)$ and comorbidities as measured the by Charlson comorbidity index ${ }^{34}(p=0.033)$.

\section{Primary Outcome: Differences in $\mathrm{HbAlc}$ Between Treatment Groups at 12 Months}

In Table 2, we present ANCOVA analyses on the ITT population after imputation of missing data. At 12 months, there were no significant differences between the active intervention groups and the control group (control is the reference; knowledge: $0.49, p=0.123$; skills: $0.23, p=0.456$; combined: 0.48 , $p=0.105)$. Higher levels of baseline HbAlc $(0.51, p<0.001)$ were significantly associated with higher levels of $\mathrm{HbA} 1 \mathrm{c}$ at
12 months. A second ANCOVA analysis was performed, adjusting for covariate imbalance at baseline (income and comorbidities). Similar to the initial analysis, only higher levels of $\mathrm{HbA} 1 \mathrm{c}$ at baseline $(0.50, p<0.001)$ were significantly associated with higher levels of $\mathrm{HbA} 1 \mathrm{c}$ at 12 months.

\section{Differences Between Treatment Groups in Rate of Change in $\mathrm{HbA}$ lc Levels over Time}

In Table 3, we present longitudinal mixed effects analyses of the ITT population after multiple imputations. The interaction terms suggest that the rates of decline in levels of $\mathrm{HbA} 1 \mathrm{c}$ over time for the active intervention groups were not significantly different from those of the control group ("time*control" is the reference; "time*knowledge": 0.06, $p=0.053$; "time*skills": $0.02, p=0.448$; "time*combined": $0.05, p=0.062$ ). Overall, there was a significant reduction in levels of $\mathrm{HbAlc}$ over time $(-0.07, p<0.001)$. Across all treatment groups, the absolute change in levels of $\mathrm{HbA} 1 \mathrm{c}$ from baseline to 3 months was 0.62 (decrease) and from baseline to 12 months was 0.6 (decrease). A second longitudinal analysis was performed, adjusting for covariate imbalance at baseline (income and comorbidities). Like the first longitudinal model, only "time" was significant, suggesting that on average, there was a significant decrease in levels of HbA1c over time $(-0.08, p<0.001)$. We repeated both the ANCOVA and longitudinal analyses for the PP population and obtained similar results. 
Table 1 Sample Demographics by Treatment Group

\begin{tabular}{|c|c|c|c|c|c|c|}
\hline Variable & All $(n=255)$ & Control $(n=64)$ & Knowledge $(n=63)$ & Skills $(n=65)$ & Combined $(n=63)$ & $p$ value \\
\hline Men & 55.3 & 51.6 & 55.6 & 61.5 & 52.4 & 0.659 \\
\hline \multicolumn{6}{|l|}{ Age (years) } & \multirow[t]{5}{*}{0.822} \\
\hline $18-34$ & 1.2 & 3.1 & 1.6 & 0.0 & 0.0 & \\
\hline $35-49$ & 22.4 & 21.9 & 25.4 & 20.0 & 22.2 & \\
\hline $50-64$ & 54.5 & 56.3 & 49.2 & 58.5 & 54.0 & \\
\hline $65+$ & 21.9 & 18.7 & 23.8 & 21.5 & 23.8 & \\
\hline \multicolumn{6}{|l|}{ Education } & \multirow{5}{*}{0.265} \\
\hline$<$ High school (HS) & 17.6 & 12.5 & 19.0 & 20.0 & 19.1 & \\
\hline HS grad & 34.9 & 42.2 & 36.5 & 40.0 & 20.6 & \\
\hline College & 40.0 & 40.6 & 38.1 & 30.8 & 50.8 & \\
\hline Graduate & 7.5 & 4.7 & 6.4 & 9.2 & 9.5 & \\
\hline \multicolumn{6}{|l|}{ Income } & \multirow[t]{5}{*}{0.013} \\
\hline$<\$ 10,000$ & 24.3 & 23.4 & 28.6 & 18.4 & 27.0 & \\
\hline$<\$ 20,000$ & 25.9 & 15.6 & 22.2 & 32.3 & 33.3 & \\
\hline$<\$ 35,000$ & 29.0 & 37.5 & 36.5 & 30.8 & 11.1 & \\
\hline$\$ 35,000+$ & 20.8 & 23.5 & 12.7 & 18.5 & 28.6 & \\
\hline Married & 43.1 & 43.7 & 41.3 & 46.1 & 41.3 & 0.934 \\
\hline \multicolumn{6}{|l|}{ Employment } & \multirow{5}{*}{0.326} \\
\hline Full/part-time & 33.4 & 39.1 & 36.5 & 30.8 & 27.0 & \\
\hline Retired & 23.9 & 18.8 & 15.9 & 24.6 & 36.5 & \\
\hline Disabled & 32.9 & 34.4 & 36.5 & 35.4 & 25.4 & \\
\hline Unemployed & 9.8 & 7.8 & 11.1 & 9.2 & 11.1 & \\
\hline \multicolumn{6}{|l|}{ Health status } & \multirow[t]{2}{*}{0.382} \\
\hline Worse & 22.0 & 28.1 & 22.2 & 15.3 & 22.2 & \\
\hline \multicolumn{6}{|l|}{ Smoking } & \multirow[t]{4}{*}{0.808} \\
\hline Never & 49.8 & 50.0 & 49.2 & 49.2 & 50.8 & \\
\hline Former & 34.9 & 34.4 & 30.2 & 40.0 & 34.9 & \\
\hline Current & 15.3 & 15.6 & 20.6 & 10.8 & 15.3 & \\
\hline \multicolumn{6}{|l|}{ Insurance } & \multirow[t]{5}{*}{0.255} \\
\hline Private & 19.6 & 23.4 & 23.8 & 16.9 & 14.3 & \\
\hline Government & 62.3 & 59.4 & 60.3 & 64.6 & 65.1 & \\
\hline None & 6.7 & 1.6 & 6.4 & 12.3 & 6.3 & \\
\hline Dual & 11.4 & 15.6 & 9.5 & 6.2 & 14.3 & \\
\hline \multicolumn{6}{|l|}{ BMI } & \multirow{4}{*}{0.602} \\
\hline$<25$ & 9.5 & 6.2 & 12.9 & 7.7 & 11.1 & \\
\hline$<30$ & 17.7 & 17.2 & 14.5 & 15.4 & 23.8 & \\
\hline $30+$ & 72.8 & 76.6 & 72.6 & 76.9 & 65.1 & \\
\hline \multicolumn{6}{|l|}{ Charlson score } & \multirow[t]{4}{*}{0.033} \\
\hline $0 / 1$ & 16.9 & 9.4 & 26.9 & 13.9 & 17.5 & \\
\hline 2 & 36.8 & 42.2 & 42.9 & 33.8 & 28.6 & \\
\hline $3+$ & 46.3 & 48.4 & 30.2 & 53.3 & 53.9 & \\
\hline Vigorous activity & 11.0 & 14.1 & 12.7 & 6.2 & 11.1 & 0.501 \\
\hline Age (years) & $57.3 \pm 10.3$ & $56.1 \pm 10.3$ & $56.5 \pm 11.5$ & $58.3 \pm 9.5$ & $58.2 \pm 10.0$ & 0.513 \\
\hline Years of education & $13.0 \pm 2.8$ & $12.9 \pm 2.8$ & $12.9 \pm 2.7$ & $12.7 \pm 2.3$ & $13.3 \pm 3.1$ & 0.588 \\
\hline Duration of diabetes & $13.2 \pm 9.0$ & $13.5 \pm 9.3$ & $12.5 \pm 8.3$ & $13.5 \pm 8.8$ & $13.7 \pm 9.7$ & 0.869 \\
\hline Baseline $\mathrm{HbA} 1 \mathrm{c}$ & $9.3 \pm 2.1$ & $9.5 \pm 2.5$ & $9.3 \pm 1.8$ & $9.2 \pm 2.1$ & $9.2 \pm 1.9$ & 0.856 \\
\hline
\end{tabular}

Results are percentage or mean $\pm S D$

\section{Mean Levels of HbAlc over Time by Treatment Group}

Figure 2 shows a graph of the observed mean levels of HbAlc over time for the four treatment groups for both the ITT and PP populations. There were no significant differences between the observed mean levels of $\mathrm{HbAlc}$ over time.

Table 2 Analyses of Covariance (ANCOVA) for Differences in Levels of HbA1c Between the Treatment Groups at 12 Months, with Baseline HbA1c as Covariate

\begin{tabular}{lllll}
\hline Parameter & Estimate & $\begin{array}{l}\text { 95\% } \\
\text { confidence } \\
\text { limits }\end{array}$ & p value \\
& Ref & Ref & Ref & Ref \\
\hline Treatment & 0.49 & -0.13 & 1.11 & 0.123 \\
$\quad$ Control & 0.23 & -0.38 & 0.83 & 0.456 \\
Knowledge & 0.48 & -0.10 & 1.07 & 0.105 \\
Skills & 0.51 & 0.39 & 0.63 & $<.001$ \\
Combined & Baseline HbA1c & & & \\
\hline
\end{tabular}

$N=255 ;$ Ref $=$ reference group
Table 3 Longitudinal Mixed Effects Analyses for Differences in the Rate of Change in Levels of HbA1c over Time Between the Treatment Groups

\begin{tabular}{|c|c|c|c|c|}
\hline \multirow{2}{*}{$\begin{array}{l}\text { Parameter } \\
\text { Treatment }\end{array}$} & \multirow[t]{2}{*}{ Estimate } & \multicolumn{2}{|c|}{$\begin{array}{l}95 \% \text { confidence } \\
\text { limits }\end{array}$} & \multirow[t]{2}{*}{$p$ value } \\
\hline & & & & \\
\hline Control & Ref & Ref & Ref & Ref \\
\hline Knowledge & -0.30 & -0.92 & 0.32 & 0.343 \\
\hline Skills & -0.20 & -0.82 & 0.43 & 0.535 \\
\hline Combined & -0.33 & -0.95 & 0.29 & 0.301 \\
\hline Time & -0.08 & -0.11 & -0.04 & $<.001$ \\
\hline \multicolumn{5}{|l|}{ Time*Treatment } \\
\hline Time*Control & Ref & Ref & Ref & Ref \\
\hline Time*Knowledge & 0.06 & -0.00 & 0.11 & 0.053 \\
\hline Time*Skills & 0.02 & -0.03 & 0.08 & 0.448 \\
\hline Time*Combined & 0.05 & -0.00 & 0.10 & 0.062 \\
\hline
\end{tabular}



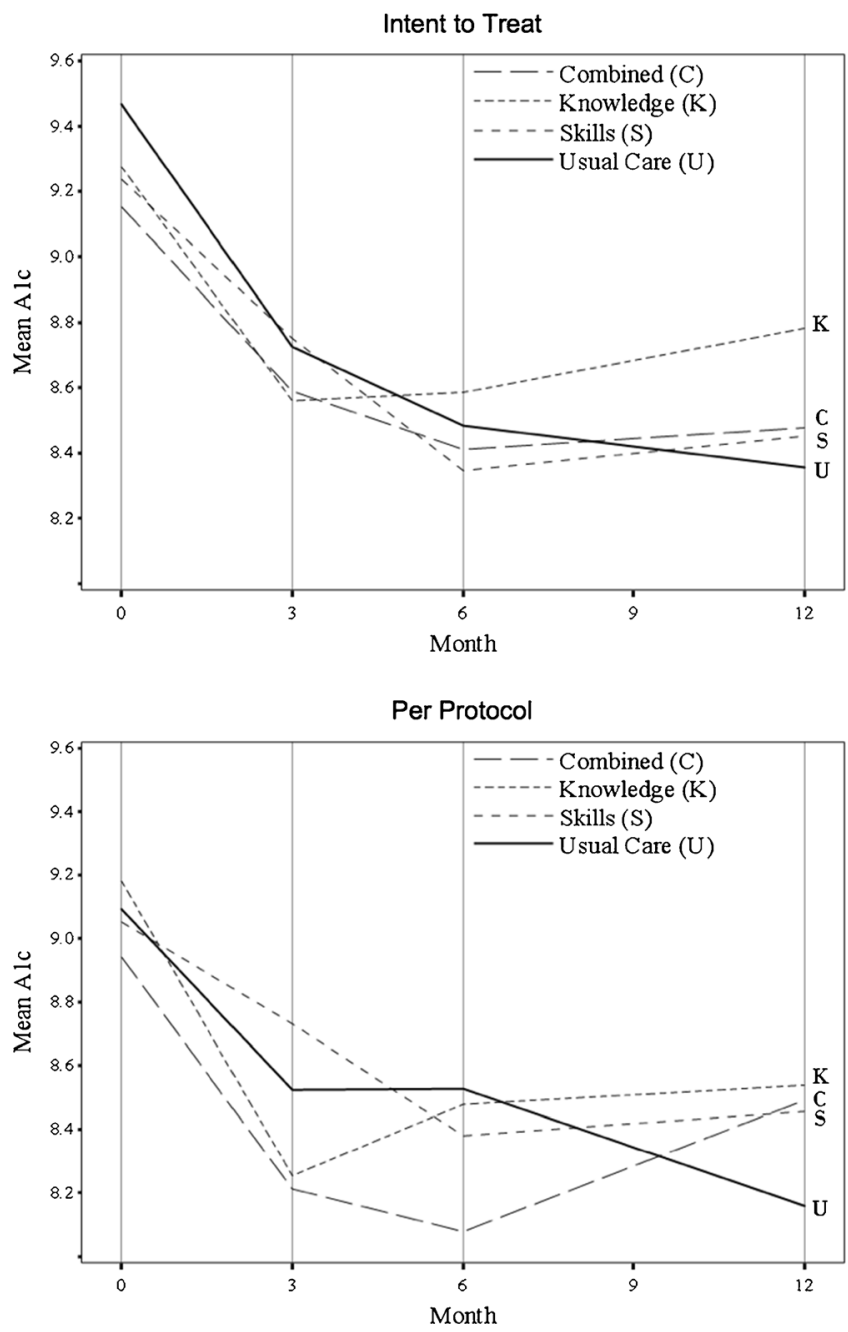

Figure 2 Mean levels of hemoglobin A1c over time by treatment group.

\section{DISCUSSION}

This study shows that combined diabetes education and skills training, diabetes knowledge alone, and skills training alone were not sufficient for achieving glycemic control at 12 months post-randomization in NHBs with poor glycemic control. There were no significant differences in HbAlc levels among treatment means at 12 months of follow-up or any significant differences among groups in the treatment slopes of HbA1c levels over time.

This study has several important features that are noteworthy. First, it is novel in that it targets a vulnerable and high-risk population with a high burden of disease and poor outcomes. ${ }^{1}$ Evidence suggests that diabetes self-management interventions are effective in improving glycemic control ${ }^{8-10,25}$; however, many of those studies have limited generalizability to NHBs. In our study, we recruited and retained a sufficient number of NHB participants with poorly controlled type 2 diabetes to establish the effectiveness of this type of intervention in this patient population. Second, it is innovative, as there are no randomized clinical trials that have compared a diabetes knowledge intervention and a skills training intervention against each other or in combination among NHBs with type 2 diabetes. Third, in addition to testing the efficacy of the separate and combined intervention arms, the intervention sessions were conducted over the telephone, a method shown to be efficacious in improving patient outcomes in multiple randomized clinical trials. ${ }^{14,16,26}$ Fourth, dose and intensity were controlled for, in that all treatment groups received the same number of sessions, for the same amount of time, over the same time. In addition, given the importance of lifestyle choices such as blood sugar monitoring, medication adherence, physical activity, and healthy eating in achieving glycemic control, participants identified the behaviors to address and were able to focus on one behavior at a time instead of multiple behaviors simultaneously. After identifying the order of the behaviors, the participants worked with the same $\mathrm{HE}$ throughout the intervention period. If the assigned $\mathrm{HE}$ left the study, the participant was quickly assigned a new HE with whom the participant worked throughout the intervention period. Fifth, study implementation was rigorously controlled, including careful a priori analyses and sample size calculations, and therapist fidelity monitoring, resulting in high study retention and session attendance, follow-up assessments up to 12 months, and examination of clinical outcomes in a vulnerable, difficult-to-treat, and understudied clinical sample.

The study had some challenges and possible explanations for the findings that are worth mentioning. First, for budgetary reasons, patients were considered eligible for the study based on HbA1c levels within the previous 12 months, which caused the period between screening eligibility and baseline visit to vary significantly. As a result, only $52 \%(132 / 255)$ of patients had $\mathrm{HbA1c}$ values $\geq 9$ at the baseline assessment, after enrollment and randomization. Values for the remaining participants had dropped below the eligibility criteria by that time. It is possible that the drop in $\mathrm{HbA} 1 \mathrm{c}$ below the a priori established eligibility range for nearly half of the patients diminished the power of the study to detect a significant difference between treatments. Second, during the time the study was conducted, staff turnover was high, especially among the HEs who conducted the telephone sessions and interventions for the treatment groups. This may have affected the study findings, in that some participants had to establish trust and rapport with the newly assigned HEs while simultaneously generating action plans for behavioral modification. The reasons for the high staff turnover remain unclear; however, we have attempted to address this problem in subsequent studies by using nurse case managers instead of HEs to conduct the interventions. Third, the control group was not a "true" control group, as they received weekly calls and general health information in the same dose, frequency, and intensity as the treatment groups. Surprisingly, after the study explanation during the consent process, several patients expressed a preference for randomization to the control group, as they preferred receiving support as part of the weekly calls, even though it was not diabetesspecific, without having to develop action plans as required in 
the other treatment groups. Fourth, all participants received 30-min calls regardless of randomization group. As such, individuals randomized to the combined arm of the study received both education and skills training in the same time frame, which could have reduced the amount of education and skills training received, resulting in an inability to detect noticeable differences in this treatment group compared to the others. Fifth, evidence supports the notion that social support may be an important component in diabetes care for African Americans. ${ }^{12,27,35}$ Under the design of this study, all groups received support. For example, the HEs offered social support to participants in the control group simply by talking and listening to them on the telephone during the sessions. Additionally, although the control group did not receive the formal diabetes education that was provided to the treatment groups, HEs felt compelled to answer their questions about diabetes, which may have affected the study results. To reduce the risk of contamination of information between treatment groups, HEs met with the principal investigator weekly for treatment fidelity reminders and to emphasize the potential effects of biasing the study results. In unpublished data from the pilot study used to design this intervention, mean $\mathrm{HbA} 1 \mathrm{c}$ for the combined treatment group dropped by $0.95 \%$ at 6 months of follow-up, whereas the mean $\mathrm{HbA} 1 \mathrm{c}$ for the control group increased by $0.3 \%$ during the same period. However, in the unpublished pilot, patients in the control group received only usual care and were not contacted by the health educators, suggesting that social support provided to the enhanced control group in the current study may have impacted the outcomes. Finally, in the pilot study, the intervention sessions were administered by a nurse, whereas we used HEs to administer the telephone sessions, and it may have taken the HEs longer to understand the tenets of motivational interviewing. This change was made due to budget constraints, in an attempt to use a lower-cost health worker to deliver the intervention.

Because of the study findings and challenges mentioned above, processes for subsequent studies have been modified to reflect lessons learned, which may be of benefit to other researchers working with African American populations with type 2 diabetes. First, because of the drop in HbAlc below the eligibility limit during the time between recruitment and baseline measurement as noted in this study, a screening visit has now been included in the enrollment process for subsequent studies, and participants are required to have $\mathrm{HbA1c}$ levels above the eligibility threshold within 2 weeks of randomization and baseline assessment. Second, given the high turnover rate of the masters-level HEs in this study, registered nurses/nurse case managers are now used to deliver the intervention. With this change in staffing, turnover is no longer a factor, and nurse case managers have been consistently providing patient-centered continuity of care. In addition, with minimal effort and time, the nurses have learned the motivational interviewing technique and have administered it appropriately in all clinical research scenarios. Third, given the strong evidence for social support as an underlying mechanism for intervention effect in African Americans, we now use a "true" control group that receives only the standard of care at the study clinics and does not have contact with the intervention nurses.

In summary, this study shows that separate and combined education and skills training are not sufficient for achieving glycemic control in NHBs with poorly controlled type 2 diabetes. Future research should focus on determining alternative strategies to improve glycemic control in this high-risk population.

\section{Acknowledgements:}

We thank the patients, providers, faculty, and staff of the Medical University of South Carolina Internal Medicine Clinic and the Ralph $\mathrm{H}$. Johnson Veterans Affairs Medical Center Primary Care Clinics who contributed to this research effort. All views and opinions expressed herein are those of the authors and do not necessarily reflect the position or policy of the NIH, MUSC, or the Ralph H. Johnson Veterans Affairs Medical Center.

Author Contributors: LEE obtained funding for the study. MG and $D C V$ performed the statistical analyses. JSW, DCV, and LEE drafted the manuscript. LEE, JSW, DCV, MG, and CPL reviewed and edited the final draft. LEE and MG are the guarantors of the work.

Corresponding Author: Leonard E. Egede, MD, MS; Division of General Internal MedicineFroedtert and Medical College of Wisconsin, Milwaukee, WI, USA (e-mail: legede@mcw.edu).

\section{Compliance with Ethical Standards:}

Conflict of Interest: The authors declare that they do not have a conflict of interest.

Funding Source: This work was supported by grant no. R01DK081121 from the National Institutes of Health/National Institute of Diabetes and Digestive and Kidney Diseases (NIH/NIDDK). The funding source had no role in the study design, data collection, data analysis, data interpretation, or writing of the report.

\section{REFERENCES}

1. Centers for Disease Control and Prevention. Diabetes report card 2014. Atlanta: Centers for Disease control and Prevention, US Dept. of Health and Human Services; 2015.

2. Blackwell DL, Lucas JW, Clarke TC. Summary health statistics for U.S. adults: National Health Interview Survey, 2012. Vital Health Stat. 2014;10(260):1-161. National Center for Health Statistics.

3. Egede LE, Dagogo-Jack S. Epidemiology of type 2 diabetes: focus on ethnic minorities. Med Clin N Am. 2005;89(5):949-75. viii.

4. Anderson RM, Herman WH, Davis JM, Freedman RP, Funnell MM, Neighbors HW. Barriers to improving diabetes care for blacks [editorial]. Diabetes Care. 1991;14:605-9.

5. Egede LE, Poston ME. Racial/ethnic differences in leisure-time physical activity levels among individuals with diabetes. Diabetes Care. 2004;27(10):2493-4

6. Jack L Jr, Airhihenbuwa CO, Namageyo-Funa A, Owens MD, Vinicor F. The psychological aspects of diabetes care. Using collaborative care to manage older adults with diabetes. Geriatrics. 2004;59:26-31.

7. Egede LE, Bonadonna RJ. Diabetes self-management in African Americans: an exploration of the role of fatalism. Diabetes Educ. 2003;29(1):105-15.

8. American Diabetes Association. Strategies for improving care. Sec. 1. In standards of medical care in diabetes-2016. Diabetes Care. 2016;39(Suppl. 1):S6-12.

9. Norris SL, Engelgau MM, Narayan KM. Effectiveness of selfmanagement training in type 2 diabetes: a systematic review of randomized controlled trials. Diabetes Care. 2001;24(3):561-87. 
10. Norris SL, Lau J, Smith SJ, Schmid CH, Engelgau MM. Selfmanagement education for adults with type 2 diabetes: a meta-analysis of the effect on glycemic control. Diabetes Care. 2002;25(7):1159-71.

11. Minet L, Moller S, Vach W, et al. Mediating the effect of self-care management intervention in type 2 diabetes: a meta-analysis of 47 randomized controlled trials. Patient Educ Couns. 2010;80(1):29-41.

12. Lirussi F. The global challenge of type 2 diabetes and the strategies for response in ethnic minority groups. Diabetes Metab Res Rev. 2010;26(6):421-32.

13. Tshiananga JK, Kocher S, Weber $\mathbf{C}$, et al. The effect of nurse-led diabetes self-management education on glycosylated hemoglobin and cardiovascular risk factors: a meta-analysis. Diabetes Educ. 2012;38(1):108-23.

14. Weinberger M, Kirkman MS, Samsa GP, et al. A nurse-coordinated intervention for primary care patients with non-insulin-dependent diabetes mellitus: impact on glycemic control and health-related quality of life. J Gen Intern Med. 1995;10(2):59-66.

15. Young RJ, Taylor J, Friede T, et al. Pro-active call center treatment support (PACCTS) to improve glucose control in type 2 diabetes: a randomized controlled trial. Diabetes Care. 2005;28(2):278-82.

16. Shea $\mathbf{S}$, Weinstock RS, Starren $\mathbf{J}$, et al. A randomized trial comparing telemedicine case management with control in older, ethnically diverse, medically underserved patients with diabetes mellitus. J Am Med Inform Assoc. 2006;13(1):40-51.

17. Raz I, Soskolne V, Stein P. Influence of small-group education sessions on glucose homeostasis in NIDDM. Diabetes Care. 1988;11(1):67-71.

18. Hanefeld $\mathbf{M}$, Fischer S, Schmechel $\mathbf{H}$, et al. Diabetes Intervention Study. Multi-intervention trial in newly diagnosed NIDDM. Diabetes Care. 1991; 14(4):308-17.

19. Bloomgarden ZT, Karmally W, Metzger MJ, et al. Randomized, controlled trial of diabetic patient education: improved knowledge without improved metabolic status. Diabetes Care. 1987;10(3):263-72.

20. Anderson RM, Funnell MM, Butler PM, Arnold MS, Fitzgerald JT, Feste CC. Patient empowerment. Results of a randomized controlled trial. Diabetes Care. 1995;18(7):943-9.

21. Gary TL, Genkinger JM, Guallar E, et al. Meta-analysis of randomized educational and behavioral interventions in type 2 diabetes. Diabetes Educ. 2003;29(3):488-501.

22. Capozza K, Woolsey S, Georgsson M, et al. Going mobile with diabetes support: a randomized study of a text message-based personalized behavioral intervention for type 2 diabetes self-care. Diabetes Spectr. 2015;28(2):83-91.
23. Miller ST, Oates VJ, Brooks MA, et al. Preliminary efficacy of group medical nutrition therapy and motivational interviewing among obese African American women with type 2 diabetes: a pilot study. J Obes. 2014;2014:345941.

24. Jennings CA, Vandelanotte C, Caperchione C, et al. Effectiveness of a web-based physical activity intervention for adults with type 2 diabetes-a randomized controlled trial. Prev Med. 2014;60:33-40.

25. Chrvala CA, Sherr D, Lipman RD. Diabetes self-management education for adults with type 2 diabetes mellitus: a systematic review of the effect on glycemic control. Patient Educ Couns. 2016;99(6):926-43.

26. Zhai YK, Zhu WJ, Cai YL, et al. Clinical- and cost-effectiveness of telemedicine in type 2 diabetes mellitus: a systematic review and metaanalysis. Medicine (Baltimore). 2014;93(28):e312.

27. Brody GH, Kogan SM, Murry VM, et al. Psychological functioning, support for self-management, and glycemic control among rural African American adults with diabetes mellitus type 2. Health Psychol. 2008;27(1 Suppl):S83-90.

28. Egede LE, Strom JL, Durkalski VL, et al. Rationale and design: telephone-delivered behavioral skills interventions for blacks with type 2 diabetes. Trials. 2010;11:35.

29. Fisher JD, Fisher B. The information-motivation behavioral skills model. In: DiClemente RJ, Crosby RA, Kegler MC, eds. Emerging theories in health promotion practice and research: strategies for improving public health. Indianapolis: Jossey-Bass, Inc; 2002.

30. Fisher JD, Fisher WA, Amico KR, Harman JJ. An informationmotivation-behavioral skills model of adherence to antiretroviral therapy. Health Psychol. 2006;25(4):462-73.

31. Osborn CY, Egede LE. Validation of an information-motivationbehavioral skills model of diabetes self-care (IMB-DSC). Patient Educ Couns. 2010;79:49-54.

32. Osborn CY, Amico KR, Fisher WA, et al. An information-motivationbehavioral skills analysis of diet and exercise behavior in Puerto Ricans with diabetes. J Health Psychol. 2010;15(8):1201-13.

33. Mensing C, Boucher J, Cypress M, et al. National standards for diabetes self-management education. Diabetes Care. 2004;27(Suppl 1):S143-50.

34. Charlson ME, Pompei P, Ales KL, MacKenzie CR. A new method of classifying prognostic comorbidity in longitudinal studies: development and validation. J Chronic Dis. 1987;40(5):373-83.

35. Marshall MC. Diabetes in African Americans. Postgrad Med J. 2005;81(962):734-40. 